\title{
Reframing, reimagining and remaking smart cities
}

Rob.Kitchin@nuim.ie

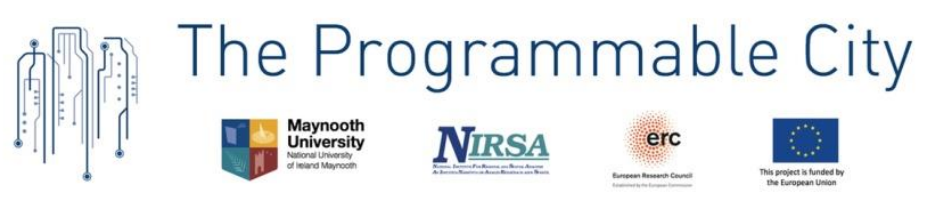

The Programmable City Working Paper 20

http://progcity.maynoothuniversity.ie/

16 August 2016

This short paper was written as an introductory framing essay for the 'Creating smart cities' workshop to be hosted by the Programmable City project at Maynooth University, Ireland, 56 September 2016.

Published as an open access pre-print on SocArXiv: https://osf.io/cyjhg/

\begin{abstract}
Over the past decade the concept and development of smart cities has unfolded rapidly, with many city administrations implementing smart city initiatives and strategies and a diverse ecology of companies and researchers producing and deploying smart city technologies. In contrast to those that seek to realise the benefits of a smart city vision, a number of critics have highlighted a number of shortcomings, challenges and risks with such endeavours. This short paper outlines a third path, one that aims to realise the benefits of smart city initiatives while recasting the thinking and ethos underpinning them and addressing their deficiencies and limitations. It argues that smart city thinking and initiatives need to be reframed, reimagined and remade in six ways. Three of these concern normative and conceptual thinking with regards to goals, cities and epistemology, and three concern more practical and political thinking and praxes with regards to management/governance, ethics and security, and stakeholders and working relationships. The paper does not seek to be definitive or comprehensive, but rather to provide conceptual and practical suggestions and stimulate debate about how to productively recast smart urbanism and the creation of smart cities.
\end{abstract}

Key words: smart cities, framing, vision, ethos, politics, urbanism 


\section{Introduction}

The first two Programmable City workshops were titled 'Code and the City' (2014) and 'Data and the City' (2015). The foci of the events were two key elements of smart city technologies - the software and digital infrastructure that enable them to function and the data which they generate, process and act upon. Attention then was concentrated on critically unpacking, interrogating and contextualising the technical apparatus and the nature of smart city technologies: their rationale, constitution, interconnections, practices, politics, work in the world, and consequences; how they enable what has been termed 'networked' or 'programmable' or 'data-driven' urbanism, or more collectively 'smart urbanism'1 - urban living, management and governance mediated by networked infrastructures and devices, algorithms and big data (see Kitchin and Perng 2016; and videos on the Programmable City website $\left.^{2}\right)$.

In this third workshop the analytical focus is shifted to the wider context in which smart city technologies (see Table 1) are being developed and deployed and what they collectively seek to produce - smart cities. The 'smart city' as a concept, ambition and actually existing deployed technologies and programmes rapidly gained traction from the late 2000s onwards. In general terms, on the one hand, new and repurposed technologies started to be more systematically targeted at urban issues and activities as potential new market opportunities and, on the other, city administrations seeking greater efficiencies and more effective answers to urban problems started to turn to potential technical solutions and to formulate and adopt smart city agendas and initiatives. Moreover, both private interests and city/national/supra-national governments saw advantage in employing smart city ideas and ideals in shaping and promoting an urban development agenda, both in terms of retrofitting or working around failing existing infrastructure and in fostering greenfield development. Of course, cities had already been using networked digital technologies and infrastructures in the delivery of services and to manage and govern urban systems for the previous half a century, but the notion and realisation of a smart city constituted a significant step change in the envisaged and actual extent, depth and use of ICTs in the running of cities.

Table 1: Smart city technologies

\begin{tabular}{|l|l|}
\hline Domain & Example technologies \\
\hline Government & $\begin{array}{l}\text { E-government systems; online transactions; city operating systems; } \\
\text { performance management systems; urban dashboards }\end{array}$ \\
\hline Security and emergency services & Centralised control rooms; digital surveillance; predictive policing; \\
\hline
\end{tabular}




\begin{tabular}{|l|l|}
\hline Transport & coordinated emergency response \\
\hline Energy & $\begin{array}{l}\text { Intelligent transport systems; integrated ticketing; smart travel cards; } \\
\text { bikeshare; real-time passenger information; smart parking; logistics } \\
\text { management; transport apps; dynamic road signs }\end{array}$ \\
\hline Waste & Smart grids; smart meters; energy usage apps; smart lighting \\
\hline Environment & Compactor bins and dynamic routing/collection \\
\hline Buildings & $\begin{array}{l}\text { loT sensor networks (e.g., pollution, noise, weather; land movement; } \\
\text { flood management); dynamically responsive interventions (e.g., } \\
\text { automated flood defenses) }\end{array}$ \\
\hline Homes & Building management systems; sensor networks \\
\hline Source: Kitchin $(2016)$ & Smart meters; app controlled smart appliances \\
\hline
\end{tabular}

Source: Kitchin (2016)

Given this step change and the embracing of smart city rhetoric and the formulation of associated policy and funding programmes by governmental bodies, the emerging market for smart city technologies, and the potential consequences with respect to urban living, management and governance, not unsurprisingly the concept of a smart city and the drive to create actually existing smart cities has attracted much media, scholarly, policy and corporate attention. However, this attention is often quite polarised with respect to its focus, intentions, and ethos. On the one side are those that develop and implement smart city technologies and initiatives, who focus on and champion the potential benefits of such technologies to society, economy and environment, but often with little critical reflection on their wider consequences beyond their desired effects (such as improving efficiency, productivity, competitiveness, sustainability, resilience, safety, security, etc). On the other side are those that critique such initiatives, focusing on issues of power, capital, equality, participation, citizenship, labour, surveillance, and alternative forms of urbanism, but often providing little constructive and pragmatic (technical, practical, policy, legal) feedback that would address their concerns while still enabling some of the benefits of smart city technologies to be realised. Indeed, it is fair to characterize smart city protagonists largely being divided into those that advocate for the promise or warn of the perils of smart cities (see Table 2).

Table 2: The promise and perils of smart cities

\begin{tabular}{|l|l|}
\hline Promises $^{3}$ & Perils $^{4}$ \\
\hline $\begin{array}{l}\text { Will tackle urban problems in ways that maximize } \\
\text { control, reduce costs, and improve services, and do so } \\
\text { in commonsensical, pragmatic, neutral and apolitical } \\
\text { ways through technical solutions. }\end{array}$ & $\begin{array}{l}\text { Treats the city as a knowable, rational, steerable } \\
\text { machine, rather than a complex system full of wicked } \\
\text { problems and competing interests. }\end{array}$ \\
\hline
\end{tabular}




\begin{tabular}{|c|c|}
\hline $\begin{array}{l}\text { Will create a smart economy by fostering } \\
\text { entrepreneurship, innovation, productivity, } \\
\text { competiveness, and inward investment. }\end{array}$ & $\begin{array}{l}\text { Promotes a strong emphasis on technical solutions } \\
\text { and overly promotes top-down technocratic forms of } \\
\text { governance, rather than political/social solutions and } \\
\text { citizen-centred deliberative democracy. }\end{array}$ \\
\hline $\begin{array}{l}\text { Will enable smart government by enabling new forms } \\
\text { of e-government, new modes of operational } \\
\text { governance, improved models and simulations to } \\
\text { guide future development, evidence-informed } \\
\text { decision making, and better service delivery, and by } \\
\text { making government more transparent, participatory } \\
\text { and accountable. }\end{array}$ & $\begin{array}{l}\text { Solutions treat cities as ahistorical and aspatial and as } \\
\text { generic markets, promoting one-size fits all technical } \\
\text { fixes rather than recognising local specificities. }\end{array}$ \\
\hline $\begin{array}{l}\text { Will produce smart mobility by creating intelligent } \\
\text { transport systems and efficient, inter-operable multi- } \\
\text { modal public transport, better and dynamic routing, } \\
\text { and real-time information for passengers and drivers. }\end{array}$ & $\begin{array}{l}\text { The technologies deployed are positioned as being } \\
\text { objective, commonsensical, pragmatic and politically } \\
\text { benign, rather than thoroughly political, reflecting the } \\
\text { views and values of their developers and } \\
\text { stakeholders. }\end{array}$ \\
\hline $\begin{array}{l}\text { Will make smart environments by promoting and } \\
\text { creating sustainability and resilience and the } \\
\text { development of green energy. }\end{array}$ & $\begin{array}{l}\text { Promotes the corporatisation and privatisation of city } \\
\text { services, with the developers of smart city } \\
\text { technologies capturing city functions as market } \\
\text { opportunities which are run for profit rather than the } \\
\text { public good, and potentially create propriety } \\
\text { technological lock-ins. }\end{array}$ \\
\hline $\begin{array}{l}\text { Will create smart living by improving quality of life, } \\
\text { increasing choice, utility, safety and security, and } \\
\text { reducing risk. }\end{array}$ & $\begin{array}{l}\text { Prioritises the values and investments of vested } \\
\text { interests, reinforces inequalities, and deepens levels } \\
\text { of control and regulation, rather than creating a more } \\
\text { socially just and equal society. }\end{array}$ \\
\hline \multirow[t]{2}{*}{$\begin{array}{l}\text { Will produce smart people by creating a more } \\
\text { informed citizenry and fostering creativity, inclusivity, } \\
\text { empowerment and participation. }\end{array}$} & $\begin{array}{l}\text { The technologies deployed have profound social, } \\
\text { political and ethical effects: introducing new forms of } \\
\text { social regulation, control and governance; extending } \\
\text { surveillance and eroding privacy; and enabling } \\
\text { predictive profiling, social sorting and behavioural } \\
\text { nudging. }\end{array}$ \\
\hline & $\begin{array}{l}\text { The technologies deployed potentially produce } \\
\text { buggy, brittle and hackable urban systems which } \\
\text { create systemic vulnerabilities across critical } \\
\text { infrastructure and compromise data security, rather } \\
\text { than producing stable, reliable, resilient, secure } \\
\text { systems. }\end{array}$ \\
\hline
\end{tabular}

Source: Based on analysis in Kitchin (2015b).

Of course, this is division is somewhat of an over-simplification. Over time, many of those promoting smart cities have come to recognize that they need to be more mindful of critiques, often trying to reframe smart city interventions in ways that are more citizen-centric and complementary to other approaches for tackling urban issues (though in general it is the framing that it is recast rather than the implementation of technologies/initiatives).

Moreover, they have come to realise that implementing a smart city initiative/strategy consists of a complex set of tasks and politics that are difficult to resolve in practice and 
require multi-stakeholder negotiations, policy changes and investments to address. For example, beyond the concerns that critics typically focus on, as set out in Table 2, the 42 interviewees - from local government, state agencies, business, universities, civic bodies and are active in smart city initiatives in Dublin - that I interviewed last year discussed over 60 different issues that can be characterised as 'critique, challenges and risks' with regards to Dublin becoming a smart city, nearly all of which are practical, pragmatic, organisational, and institutional in nature (concerning issues such as personnel capacity/competency, funding/procurement, processes and procedures, structures, coordination, priorities, strategy, leadership, policy/law, competing interests, etc.), rather than being political or ideological (see Figure 1). Similarly, many critics have recognized that smart city technologies do provide workable solutions for many urban issues, are often well-liked by citizens, and such technologies are not only here to stay but are going to become more entrenched in the future. Their focus of attention is thus on modifying the formulation and ethos of smart city initiatives and implementing them in ways that minimize perils, rather than seeking their abandonment.

\section{Figure 1: Critique, challenges and risks in seeking to become a smart city}

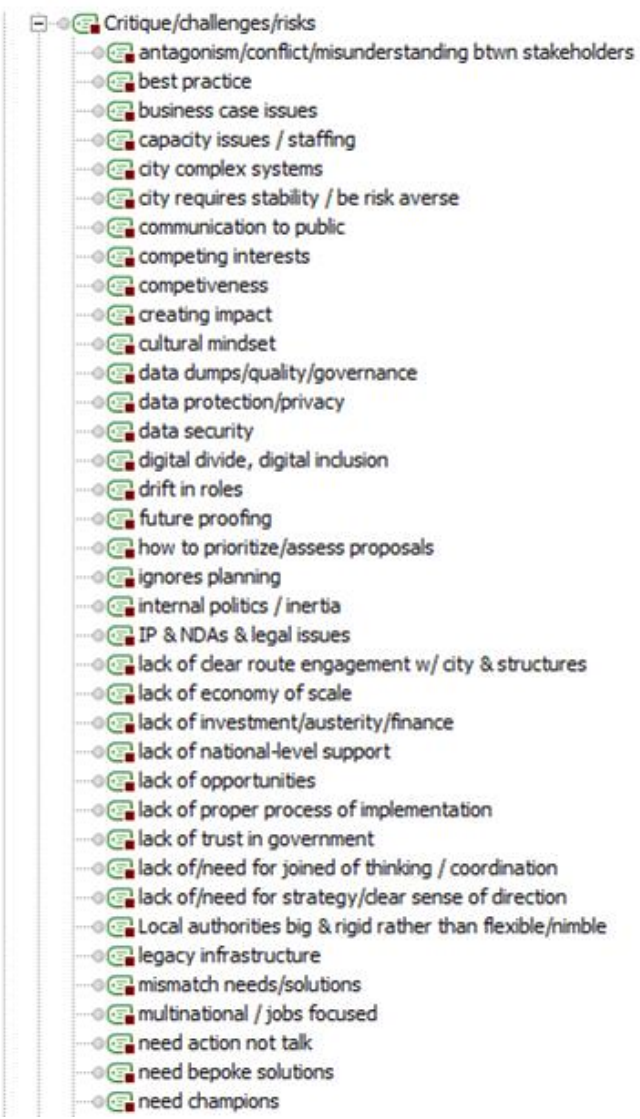

- need CIO, CTO, CDO

- . need for education / data literacy

needs alignment with wider planning

non-interoperability/lack of integration (siloes)

not using industry located here

- $p$ ath dependency

Political geography of city

Poor choice/implementation

Privatisation

Pprocurement issues

P. proprietary systems/data

Q.

sceptism

- setbacks

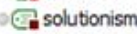

- standardisation / standards

Gesurveillance

Fustainability/ pilots

. too many barriers to implementation

. transparency lack of comms to / indusion citizens

transparency/openness vs dosed/propriety

T. unanticipated consequences

. under-utlising/not using installed tech

. Unofficial state aid

-..-upgrade treadmill

Fvariances between LAs

. vendor-ted or tech-led vs city-led or citizen-ted

. wasting investment

weak/need for governance/leadership

Source: MAXQDA coding of Rob Kitchin's Dublin interviews (conducted $4^{\text {th }}$ Feb to $7^{\text {th }}$ May 2015) 
Most of the contributors to this workshop, I think it is fair to characterize, lean towards the perils, challenges and risk side of smart city debates. The danger therefore is that the discussion becomes heavily weighted towards critique, with little consideration of political, social or practical interventions and reorientations. As such, a principal aim of the workshop, as I see it, is to critically examine the creation of smart cities and to try and formulate new visions of smart urbanism that seek to gain the promises of smart cities while minimizing their perils; to explore the various critiques of smart city rhetoric and deployments and to suggest social, political and practical interventions that would enable better designed and more equitable and just smart city initiatives. Of course, producing a form of smart urbanism that realises promises while curtailing perils is no easy task - and is perhaps impossible at a deep ideological level - given the many stakeholders and vested interests involved and their differing politics, approaches, aims and ambitions. Nonetheless, trying to negotiate across these interests and ambitions is necessary if critique is to transition - even if in partial and limited ways - into the reframing, reimagining and remaking of smart cities. In a sense, we are inviting participants to imagine they have been asked by a city or company or community for concrete advice on how they might productively address and ameliorate the most troubling aspects of any critique that might be levelled against them, in a scenario where networked and mobile ICTs are already firmly embedded in the fabric and running of cities (in other words, simply calling for a return to analogue cities and nonnetworked urban development is untenable).

\section{Reframing, reimagining and remaking smart cities}

As a means of initiating debate and a consideration of interventions that address shortcomings, challenges and risks of smart city developments, I contend that the reframing, re-imagining and remaking of smart city thinking and implementation needs to occur in at least six broad ways. These are reframing, re-imaging and remaking of: goals; cities; epistemology; management/governance; ethics and security; and stakeholders and working relationships. The first three of these relate to more fundamental philosophical concerns the normative, ontological, epistemological - the latter more practical and political matters.

\section{Goals}

At one level, the goals of creating smart cities are already established - as detailed in the promises column of Table 2 - they are to improve quality of life and create more efficient, productive, competitive, sustainable, and resilient cities. At a more profound, normative 
level, however, I think the goals of smart cities are less well defined and cogently established. There is a need, I feel, for a more sustained engagement with normative questions, such as 'for whom and what purpose are smart cities being developed?' Are smart cities primarily about - or should be about: creating new markets and profit?; facilitating state control and regulation?; addressing their anticipatory logics (demographic shifts, global climate change, fiscal austerity $\left.{ }^{5}\right)$ ?; improving the quality of life of citizens?

Indeed, the fundamental question of "what kind of cities do we want to create and live in?' is largely reduced to technical issues within smart city discourse (e.g., a city where the traffic flows more efficiently, energy consumption is reduced, the crime rate is lowered, etc.) as opposed to considering this at a more profound level with respect to issues such as fairness, equity, justice, citizenship, democracy, governance and political economy. In fact, rather than start with this kind of fundamental question and then formulating a strategy to realise it, the impression one gains from encountering smart city initiatives is that the starting point is the technology and then to partially approach the question from the perspective of what core issue (e.g., sustainability) its technical intervention (reducing traffic) might address. In other words, the means is post-justified by ends, rather than the ends shaping the means.

Grabbling with more normative questions is important because they set the wider framework within which smart city agendas and initiatives are formulated, deployed and run. At present, few cities or companies can coherently articulate their smart city vision and goals in normative terms beyond technical, aspirational statements (e.g., Dublin will be 'open, connected, engaged'; Cork will be 'innovating, creating, connecting'). Not unsurprisingly, smart city initiatives are somewhat haphazard, uncoordinated, and opportunistic, and where a more fully realised strategy has been formulated (which is still rare) contradictory with respect to other urban policies. City administrations, in particular, as the core bodies driving and implementing smart city initiatives need to start the process of divining their smart city strategies by considering these normative questions, not simply by holding workshops to consider which urban problems to prioritize for smart city solutions.

\section{Cities}

For the most part, smart city advocates frame the city as a technical entity which consists of a set of knowable and manageable systems (or system of systems) that act in largely rational, mechanical, linear and hierarchical ways and can be steered and controlled through technical levers, and that urban issues can be solved with technical solutions ${ }^{6}$. Moreover, 'the city' is 
treated as a generic analytical category, meaning a solution developed for one city can be transferred and replicated elsewhere. Such a view of cities is limited and limiting; not only does this narrow, technical view fail to capture the full complexity of cities, but it also constrains the potential benefits that smart city technologies might produce by producing solutions that are not always attuned to the wider contexts in which urban problems are situated.

Cities are not simply technical systems that can be steered and controlled in the same way that a car or plane can be. Nor can urban issues be simply solved with technical solutions. Cities are complex and ever-evolving, jammed packed with a multitude of interdependent, contingent and relational actors, actants, processes and relationships. They are full of culture, politics, competing interests, and wicked problems. They are difficult to predict and often develop over time in capricious ways. Moreover, no two cities hold the same qualities, having different histories, populations, cultures, economies, politics, legacy infrastructures and systems, political and administrative geographies, modes of governance, sense of place, hinterlands, interconnections and interdependencies with other places, and so on.

Intrinsically, city administrations know that cities are complex, open, multiscalar, contingent and relational, yet they often practice a form of strategic essentialism and seek to tackle urban issues through narrow technical fixes that ignores wider interdependencies. Likewise, companies developing smart city technologies perform the same strategic essentialism, though they often have less appreciation of the full complexities, processes, practices and politics of managing and governing a city (I have been asked several times by companies to explain how cities and city administration work). For smart city initiatives to work well they need to be conceptualized and contextualized within a broader and richer understanding of what a city is and how it works in practice. In other words, smart city advocates need to recognize and accommodate a more nuanced, relational understanding of cities and to appreciate and take into account the diversity and complexity of cities in their formulations. This also requires smart city advocates to recognize that their technical solutions will not work on their own and need to be positioned alongside and integrated with other solutions that are more social, political, legal, and community-orientated, and they should articulate and promote what that suite of solutions might be. 


\section{Epistemology}

How can we know the city? To understand and explain it? And then act on this knowledge? These are epistemological questions. In general, smart city technologies, and associated rhetoric and science (urban science and urban informatics), are founded on big analytics. In short, this means algorithms are used to process vast quantities of real-time data in order to dynamically manage a system and to make future predictions. There are two issues with this approach. The first is that these data are typically quantitative and one-dimensional in nature, limited in scope (e.g., sensor readings, camera images, clickstreams, admin records), and do not provide a full and multidimensional picture of the city. They therefore provide a very narrow, selective view of city systems and life, prioritizing data that are machine-readable and excluding far more information than they include. The second is that the scientific approach adopted for data generation, analysis (e.g., statistics and modelling) and communication (e.g., data visualizations via urban dashboards) is reductionist, mechanistic, atomizing, essentialist, and deterministic in how it produces knowledge about cities. It is an approach that decontextualizes a city and its systems from history, its politics and political economy, its culture and communities, the wider set of social, economic and environmental relations that frame its development, and its wider interconnections and interdependencies that stretches out over space and time. Moreover, with its claims to objectivity and neutrality, such an approach tends to marginalize and replace other ways of examining the city (such as through focus groups, interviews, surveys, etc.) and other forms of knowing such as phronesis (knowledge derived from practice and deliberation) and metis (knowledge based on experience).

This is not to say that this approach does not produce useful or valuable knowledge. Rather it is to recognize that such knowledge is partial, based on a narrow realist epistemology and instrumental rationality, and that it needs to, on the one hand, reframe its epistemology to openly acknowledge its situatedness, positionality, contingencies, assumptions, and shortcomings, and on the other hand, complement such knowledge with other forms of knowing, such as phronesis and metis ${ }^{7}$. Such an epistemological move dovetails with the reframing of cities to recognize their multiple, complex, interdependent nature. Without this change in epistemology, the underlying scientific rationalities of smart city technologies and approach will remain anaemic, partial and open to significant underperformance and failure ${ }^{8}$. 


\section{Management/governance}

Smart city technologies enact algorithmic governance and forms of automated management ${ }^{9}$. City systems are measured, with vast quantities of data generated, processed, converted into metrics, analysed and visualised, and outcomes assessed and acted upon in an automatic, automated and autonomous fashion. Such automated management facilitates and produces instrumental and technocratic forms of governance and government. That is, rote, procedural, rule-driven, top-down, autocratic means of managing how a system functions and how it processes and treats individuals within those systems. Algorithmic governance is the technical means to manage a city understood in technical terms: wherein there is a belief that the city can be steered and controlled through algorithmic levers. For its advocates, such a data-driven, algorithmic approach ensures rational, logical and impartial governance and optimal performance.

Instrumental and technocratic forms of governance enacted by smart city technologies have been critiqued in a number of ways ${ }^{10}$. First, far from being impartial smart city technologies have built in normative values and judgements about how systems should perform, and how they assess and manage outcomes, with these hardwired into the underlying software. Moreover, they have normative effects in terms of how they are deployed to shape and modify system, citizen and institutional behaviour. Second, they are narrow in scope and reductionist and functionalist in approach, rather than taking a more democratic, policy-led or holistic approach to an issue, and ignoring wider cultural, social and political contexts and means to tackle urban issues. Third, they are top-down, centrallycontrolled and managerialist in orientation, often introduced by bureaucrats (city managers) rather than elected officials or being developed in conjunction with local communities. Indeed, local communities are often little consulted in decision-making processes concerning smart city technologies and their form, implementation and operation (and certainly not as they would be concerning planning and development plans). Fourth, the exhaustive and indexical nature of data generation converts every city system adopting such technologies into a surveillance machine, with the interlinking of such systems and the processing and analysing of such data raising a number of ethical concerns. Fifth, they provide 'sticking plaster' or 'work around' solutions, rather than tackling root and structural causes of an issue or being used in conjunction with other policies or instruments.

Just as cities need to be conceptualised in a broader and more synoptic way by smart city advocates, so does city management and governance. While it is undoubtedly the case that many smart city technologies do enable more efficient and effective management of city 
systems, and provide convenience and improve services, they are not sufficient solutions on their own to the diverse range of issues facing cities and themselves cause some concerns. Instead, they need to be introduced and implemented through processes co-creation and coproduction between city administrations, companies and citizens; be open and transparent in their formulation and operation, including using open platforms and standards where possible; and be used in conjunction with a suite of aligned interventions, policies and investments that seek to tackle issues in complementary ways, blending technical, social, political and policy responses. Not enough work has been done to consider how best to achieve such a blended, open, and co-produced form of urban management and governance and how it anchors the central operational ethos and approach of smart city strategies ${ }^{11}$.

\section{Ethics and security concerns}

Smart city technologies generate huge quantities of data about systems and people, much of them in real-time and at a highly granular scale. These data can be put to many good uses; however, generating, processing, analysing, sharing and storing large amounts of actionable data also raise a number of concerns and challenges. Key amongst these are privacy, predictive profiling, social sorting, anticipatory governance, behavioural nudging, control creep, data protection, and data security. Indeed, many smart city technologies capture personally identifiable information and household level data about citizens - their characteristics, their location and movements, and their activities - link these data together to produce new derived data, and use them to create profiles of people and places and to make decisions about them. As such, there are concerns about what a smart city means for people's privacy and what privacy and predictive privacy harms might arise from the sharing, analysis and misuse of urban big data ${ }^{12}$. In addition, there are questions as to how secure smart city technologies and the data they generate are from hacking and theft and what the implications of a data breach are for citizens.

To date, the approach to these issues has been haphazard, uncoordinated and partial. As suggested with respect to city management and governance in general, addressing privacy and security issues requires a multi-pronged set of interventions that ideally are coherently aligned and implemented in conjunction with one another. In a recent report for the Irish Government's Data Forum ${ }^{13}$ I outlined such an approach, suggesting four types of intervention, each consisting of a number of mediations. First, market-driven solutions: including the development of industry standards, stronger self-regulation, and the reframing of privacy and security as a competitive advantage. Second, technological solutions: 
including end-to-end encryption, access controls, security controls, audit trails, backups, upto-date patching, and privacy enhancement tools. Third, policy, regulatory and legal solutions: including revised fair information practice principles, privacy by design, security by design, and education and training. Fourth, governance and management solution at three levels: vision and strategy - smart city advisory boards and published strategies; oversight of delivery and compliance - smart city governance, ethics and security oversight committees; and day-to-day delivery - core privacy/security teams, smart city privacy/security assessments, and computer emergency response teams.

Using these solutions together would provide a balanced, pragmatic approach that enable the rollout of smart city technologies and initiatives but in a way that is not prejudicial to people's privacy, actively work to minimise privacy and predictive privacy harms, curtail data breaches, and tackle cybersecurity issues. They also work across the entire life-cycle (from procurement to decommissioning) and span the whole system ecology (all its stakeholders and components). Collectively they promote fairness and equity, protect citizens and cities from harms, and enable improved governance and economic development. Moreover, they do so using an approach that is not heavy handed in nature and is relatively inexpensive to implement. They are by no means definitive, but would in my opinion enable a more ethical, principle-led approach to the design and implementation of smart cities. Failing to tackle these issues will undermine and curtail smart city initiatives and public support for them.

\section{Stakeholders and working relationships}

As noted, smart city protagonists are often divided into those who develop, implement and promote smart city technologies and initiatives, and those who critique such endeavours. While the former have been starting to respond to critique, albeit in rather limited ways, and the latter have started to make more active interventions, there is still much more work to be done to bring different stakeholders into dialogue and working relationships. There is certainly a lot of learning that needs to be done: by city administrations with respect to developing smart city strategies and procuring and deploying smart city technologies; by companies with respect to how cities are managed and function and balancing private gain with public good; by communities involved in or living with smart city initiatives; and by researchers and consultants who are seeking to understand what is unfolding in different cities and contexts ${ }^{14}$. This learning will progress most effectively through co-creation and coproduction, with stakeholders working together. 
This requires all stakeholders to be open to working and learning from one another for the common purpose of improving the quality of lives for citizens and how cities are managed and governed. With respect to academia, this means critical scholars have to become more applied in orientation: to give constructive feedback and guidance and to set out alternatives and to help develop strategies, not just provide critique. This does not mean that critique is not valuable in of itself. Nor does it mean dumbing down or abandoning a critical position or emancipatory politics or 'getting into bed with the enemy'. It means putting principles into action - to translate them into practical and political outcomes. Our own endeavours have demonstrated that smart city stakeholders are open to robust exchanges and are prepared to rework initiatives and change direction, especially if we are willing to work with them and others to realise any reframing, reimagining and remaking involved. That said, not all city administrations or companies want such collaborations, or it might be very difficult to align differing ideological beliefs, in which case external critique might be the only option. However, in my view, such critique ideally also needs to suggest alternatives - whether ideological or practical - and to support the work of other oppositional groups (such as local communities or NGOs).

\section{Conclusion}

The purpose of this short paper has been to set out some of the key shortcomings, challenges and risks associated with smart city technologies and initiatives and to suggest how smart city thinking and implementation might be productively reframed, reimagined and remade in six ways: three that concern normative and conceptual thinking with regards to goals, cities and epistemology; and three concern more practical and political thinking and praxes with regards to management/governance, ethics and security, and stakeholders and working relationships. The aim has not been to be definitive or comprehensive, but rather to provide some initial ideas and contentions - some more conceptual and philosophical, some more practical and political - that act as provocations for discussion and debate. As such, while the six interventions detailed offer a set of initial entry points, my hope is that they are creatively reworked and extended through our deliberations during the workshop.

\section{Notes}

1. Graham and Marvin (2001); Dupuy (2008); Kitchin (2011, 2014a, 2015a); Greenfield (2013); LuqueAyala and Marvin (2015); Marvin et al. (2016)

2. http://progcity.maynoothuniversity.ie/videos/; a second book - 'Data and the City' - is currently being edited. 
3. Compiled from Giffinger et al. (2007); Hollands (2008); Cohen (2012); Townsend (2013)

4. Compiled from Cerrudo (2015); Datta (2015); Dodge and Kitchin (2005); Elwood and Leszczynski (2013); Graham (2005); Greenfield (2013); Hill (2013); Kitchin (2014); Kitchin and Dodge (2011); Kitchin et al. (2015); Mattern (2013); Morozov (2013); Shelton et al. (2015); Townsend (2013); Vanolo (2014).

5. Merricks White (2016).

6. See Mattern $(2013,2014,2015)$ and Kitchin et al. (2015).

7. See Kitchin (2014b); Kitchin et al. (2015).

8. See Flood (2011).

9. Kitchin and Dodge (2011).

10. See Hill (2013); Greenfield (2013); Kitchin (2014a; 2016).

11. See Goldsmith and Crawford (2014).

12. Kitchin and Dodge (2011); Baracos. and Nissenbaum (2014); Edwards (2016); Kitchin (2016); Taylor et al. (2016); Leszczynski (in press).

13. Kitchin (2016).

14. Kitchin (2015c).

\section{Acknowledgement}

The research for this paper was funded by a European Research Council Advanced Investigator grant, The Programmable City (ERC-2012-AdG-323636).

\section{References}

Baracos, S. and Nissenbaum, H. (2014) Big data's end run around anonymity and consent. In Lane, J., Stodden, V., Bender, S. and Nissenbaum, H. (eds) Privacy, Big Data and the Public Good. Cambridge University Press, Cambridge, pp. 44-75.

Cerrudo, C. (2015) An Emerging US (and World) Threat: Cities Wide Open to Cyber Attacks.

Securing Smart Cities, securingsmartcities.org/wpcontent/uploads/2015/05/CitiesWideOpenToCyberAttacks.pdf (last accessed 12 October 2015)

Cohen, B. (2012) What Exactly Is A Smart City? Fast Co.Exist, 19 September, www.fastcoexist.com/1680538/what-exactly-is-a-smart-city (last accessed 28 April 2015)

Datta, A. (2015) New urban utopias of postcolonial India: 'Entrepreneurial urbanization' in Dholera smart city, Gujarat. Dialogues in Human Geography 5(1): 3-22.

Dodge, M. and Kitchin, R. (2005) Codes of life: Identification codes and the machine-readable world. Environment and Planning D: Society and Space. 23(6): 851-881.

Dupuy, G. (2008) Urban Networks - Networked Urbanism. Techne Press, Netherlands.

Edwards, L. (2016) Privacy, security and data protection in smart cities: A critical EU law perspective. European Data Protection Law Review 2(1): 28-58.

Elwood, S. and Leszczynski, A. (2011) Privacy reconsidered: New representations, data practices, and the geoweb. Geoforum 42: 6-15.

Flood, J. (2011) The Fires: How a Computer Formula, Big Ideas, and the Best of Intentions Burned Down New York City--and Determined the Future of Cities. Riverhead, New York. 
Giffinger, R., Fertner, C., Kramar, H., Kalasek, R., Pichler-Milanović, N. and Meijers, E. (2007) Smart cities: Ranking of European medium-sized cities. Centre of Regional Science, Vienna UT. www.smart-cities.eu/download/smart_cities_final_report.pdf (last accessed 12 October 2015)

Goldsmith, S. and Crawford, S. (2014) The Responsive City: Engaging Communities Through DataSmart Governance. Jossey-Bass, San Francisco.

Graham, S. and Marvin, S. (2001) Splintering Urbanism: Networked Infrastructures, Technological Mobilities and the Urban Condition. London: Routledge.

Graham, S. (2005) Software-sorted geographies. Progress in Human Geography 29(5): 562-80.

Greenfield, A. (2013) Against the Smart City. New York: Do Publications.

Hill, D. (2013). On the smart city: Or, a 'manifesto' for smart citizens instead. City of Sound, 1 February. www.cityofsound.com/blog/2013/02/on-the-smart-city-a-callfor-smart-citizensinstead.html (last accessed 5 February 2013)

Hollands, R.G. (2008) Will the real smart city please stand up? City, 12(3): 303-320.

Kitchin, R. (2011) The Programmable City. Environment and Planning B 38: 945-951

Kitchin, R. (2014a) The real-time city? Big data and smart urbanism, GeoJournal, 79(1): 1-14.

Kitchin, R. (2014b) Big data, new epistemologies and paradigm shifts. Big Data and Society 1 (April-June): 1-12.

Kitchin, R. (2015a) Data-driven, networked urbanism. Programmable City Working Paper 14. http://ssrn.com/abstract=2641802

Kitchin, R. (2015b) The promise and peril of smart cities. Journal of the UK Society of Computers and Law. http://www.scl.org/site.aspx?i=ed42789, June.

Kitchin, R. (2015c) Making sense of smart cities: addressing present shortcomings. Cambridge Journal of Regions, Economy and Society 8 (1): 131-136

Kitchin, R. (2016) Getting smarter about smart cities: Improving data privacy and data security. Data Protection Unit, Department of the Taoiseach, Dublin, Ireland. http://www.taoiseach.gov.ie/eng/Publications/Publications_2016/Smart_Cities_Report_January_2 016.pdf

Kitchin, R. and Dodge, M. (2011) Code/Space: Software and Everyday Life. Cambridge, MA: MIT Press. Kitchin, R. and Perng, S-Y. (eds) (2016) Code and the City. Routledge, London.

Leszczynski, A. (in press) Geoprivacy. In Kitchin, R., Lauriault, T. And Wilson, M. (eds) Understanding Spatial Media. Sage, London.

Luque-Ayala, A. and Marvin, S. (2015) Developing a critical understanding of smart urbanism? Urban Studies 52(12): 2105-2116.

Marvin, S., Luque-Ayala, A. and McFarlane, C. (eds.) (2016) Smart Urbanism: Utopian Vision or False dawn? Routledge, London. 
Mattern, S. (2013) Methodolatry and the art of measure: The new wave of urban data science. Design Observer: Places. 5 November. designobserver.com/places/feature/0/38174/ (last accessed 15 November 2013)

Mattern, S. (2014) Interfacing urban intelligence. Places: Design Observer http://places.designobserver.com/feature/how-do-we-interface-with-smart-cities/38443/ (last accessed 17 July 2014).

Mattern, S. (2015) Mission Control: A History of the Urban Dashboard, Places Journal https://placesjournal.org/article/mission-control-a-history-of-the-urban-dashboard/ (last accessed 16 April 2015).

Merricks White, J. (2016) Anticipatory logics of the smart city's global imaginary. Urban Geography 37(4): 572-589.

Morozov, E. (2013) To Save Everything, Click Here: Technology, Solutionism, and the Urge to Fix Problems That Don't Exist. New York: Allen Lane.

Shelton, T., Zook, M. and Wiig, A. (2015) The 'actually existing smart city'. Cambridge Journal of Regions, Economy and Society 8: 13-25.

Taylor, L., Richter, C., Jameson, S. and Perez del Pulgar, C. (2016) Customers, users or citizens? Inclusion, spatial data and governance in the smart city. University of Amsterdam. https://pure.uvt.nl/portal/files/12342457/Customers_users_or_citizens_Taylor_Richter_Jameson_P erez_de_Pulgar_2016.pdf (last accessed 16 August 2016)

Townsend, A. (2013) Smart Cities: Big data, Civic Hackers, and the Quest for a New Utopia. New York: W.W. Norton \& Co.

Vanolo, A. (2014) Smartmentality: The smart city as disciplinary strategy. Urban Studies 51(5) 883898. 